Jahangirnagar University J. Biol. Sci. 6(2): 47-58, 2017 (December)

\title{
Evaluation of antioxidant and chemopreventive effect of Cocos nucifera $\mathbf{L}$.
}

\author{
Shrabanti Dev*, Anha Afrin Shefa, Archana Mandal, Projit Roy Gayen, Kaniz \\ Asma, Md. Abdullah Al Bari, Masum Shahriar ${ }^{1}$ and Asish Kumar Das \\ Pharmacy Discipline, Khulna University, Khulna-9208, Bangladesh
}

\begin{abstract}
This study revealed the antioxidant and anticancer activities of the ethanolic extract of the tender fruits of Cocos nucifera. In antioxidant screening, $\mathrm{IC}_{50}$ value was found to be $7.71 \mu \mathrm{g} / \mathrm{mlfor}$ ascorbic acid and $44.67 \mu \mathrm{g} / \mathrm{ml}$ for $C$. nucifera fruits. The phenolic content, total flavonoid and total tannin content were $537.89 \mathrm{mg} \mathrm{GAE} / 100 \mathrm{gm}, 40.69 \mathrm{mg}$ of QE/100 gm and $44.61 \mathrm{mg}$ of GAE/100 gm of dry powder of $C$. nucifera respectively. In DMBA and croton oil-induced skin cancer in model mice,the extract significantly decreased the number, size, yield and burden of tumor when compared with carcinogenic control. The extract increased the level of natural antioxidants like GSH, SOD and Catalase. Moreover, substantial decrease in SGPT, SGOT (liver activity marker) was observed at different doses ofthe crude extract. Lipid profile of mice treated with $C$. nucifera was brought back to normal level to some extent when compared to carcinogenic control. In conclusion, $C$. nucifera fruits have antioxidant activity as well as preventive role on cancer initiation and propagation without major toxicity.
\end{abstract}

Key words: Cocos nucifera, DMBA, Croton oil, GSH, SOD, Catalase.

\section{INTRODUCTION}

Cancer is one of the most life-threatening diseases, with more than 100 different types occurring due to some molecular changes within the cell. It is the third leading cause of death worldwide following cardiovascular and infectious diseases. Cancer is the second leading cause of death globally, and was responsible for 8.8 million deaths in 2015 . Globally, nearly 1 in 6 deaths is due to cancer. (WHO, 2017; Kelloff, 2008). The disease is widely prevalent, and in the West, almost a third of the population develops cancer at some point of time during their life. Although the mortality due to cancer is high, many advances have been made both in terms of treatment and understanding the biology of the disease at the molecular level (Swerdlow et al., 2010).

Moreover, it is increasingly being realized that many of today's diseases are due to the "oxidative stress" that results from an imbalance between the formation and neutralization of prooxidants. Oxidative stress is initiated by free radicals, which seek stability through electron pairing with biological macromolecules such as proteins, lipids, and DNA in healthy human cells and cause protein and DNA damage along with lipid peroxidation. These changes contribute to cancer, atherosclerosis, cardiovascular diseases, aging, and inflammatory diseases (Braca, 2002; Maxwell, 1995). All cells are exposed to oxidative

\footnotetext{
${ }^{1}$ Department of Pharmacy, Jahangirnagar University, Savar, Dhaka-1342, Bangladesh

* Corresponding author. Email: dshraban@yahoo.com
} 
stress, and thus, oxidation and free radicals may be important in carcinogenesis at multiple tumor sites.

Due to lack of effective drugs, cost of chemotherapeutic agents, and the side effects of anticancer drugs, it's the demand of the time to develop better drugs for cancer treatment. Therefore, efforts are still being made to search for effective naturally occurring anticarcinogens that would prevent, slow, or reverse cancer development. Medicinal plants have a special place in the management of cancer. It is estimated that plant-derived compounds in one or the other way constitute more than $50 \%$ of anticancer agents (Babior et al., 2000; Nipun et al., 2011).

Cocos nucifera (Family: Arecaceae) is widely known withits English name coconut. The plant is cultivated widely worldwideand being used as a staple food crop. Moreover, local people also use it as a source of wood and handicrafts (Edward et al., 2006). The various products of coconut include tender coconut water, copra, coconut oil, raw kernel, coconut cake, coconut toddy, coconut shell and wood based products, coconut leaves and coir pith. The parts of its fruit like coconut kernel and tender coconut water have numerous medicinal properties such as antibacterial, antifungal, antiviral, anti-parasitic, antidermatophytic, antioxidant, hypoglycemic, hepatoprotective, immunostimulant. Coconut water and coconut kernel contain microminerals and nutrients, which are essential to human health, and hence coconut is used as food by the people in the globe, mainly in the tropical countries (Lima EBC et al., 2015). A previous study also reported that in the traditional medicine in northeastern Brazil, coconut husks have been used for the treatment of diarrhea and arthritis (Esquenazi et al., 2002).Coconut oil has been confirmed to possess antimicrobial, antiviral and antiprotozoal activities (Enig, 2000). The aim of the present study is to elucidate the antioxidant and chemopreventive activity of $C$. nucifera tender fruit extract.

\section{MATERIALS AND METHODS}

Sample Collection: The fruits of Cocos nucifera were collected from surrounding area of Khulna university.

Drying \& Grinding: The collected fruits were air dried for three weeks and were ground into a fine powder with the help of a suitable grinder. The powder was stored in an airtight container and kept in a cool, dark and dry place until analysis commenced.

Extraction: Dried fruit powder sample of $400 \mathrm{~g}$ was taken in $1500 \mathrm{ml}$ of $99 \%$ ethanol and kept in air tight bottle. After 7 days ethanol was filtered by What man No. 1 filter paper. The filtrate wasdried with rotary evaporator at $40^{\circ} \mathrm{C}$ and kept in the refrigerator for further use. The yield was $11.2 \%$ of the dry weight of powder.

Test Animals: Male Swiss albino mice (6-7 weeks) were used for this study. Mice were maintained in animal house at temperature $22 \pm 3^{\circ} \mathrm{C}$ and 12 hour light and dark cycle. Mice were house in polypropylene cage. Standard food and water were provided ad 
libitum. All experiments were performed following the standard guidelines developed by the ethical committee of Khulna University, Bangladesh.

Chemicals: Ascorbic acid, Folin-Ciocalteu's phenol reagent, (+)-Catechin, Gallic acid, Super oxisde dismutase (SOD), Catalase, 7,12-Dimethyl Benzanthracene (DMBA) and croton oil were purchased from Sigma-Aldrich Co. (St. Louis,MO). DPPH was purchased from Wako Pure Chemical Industry Ltd., Osaka, Japan. All other chemicals and reagents were of analytical grade.

\section{Evaluation of antioxidant activity}

i) DPPH radical scavenging activity: The anti-oxidant potential of the ethanol extract was determined on the basis of their scavenging activity of the stable 1, 1-diphenyl-2picryl hydrazyl (DPPH) free radical. DPPH is a stable free radical containing an odd electron in its structure and usually utilized for detection of the radical scavenging activity in chemical analysis. The aliquots of the different concentrations $(5-100 \mu \mathrm{g} / \mathrm{mL})$ of the extract were added to $6 \mathrm{~mL}$ of a $0.004 \% \mathrm{w} / \mathrm{v}$ solution of DPPH. Absorbance at $517 \mathrm{~nm}$ was determined after $30 \mathrm{~min}$, and $\mathrm{IC}_{50}$ (Inhibitory conc. 50\%) was determined. $\mathrm{IC}_{50}$ value denotes the concentration of sample required to scavenge 50\% of the DPPH free radicals (Gupta et. al., 1971). The percent inhibition is calculated using the formula:

$\%$ inhibition $=($ Blank Absorbance - Sample Absorbance/ Blank Absorbance $) \times 100$

ii) Determination of Total Phenolic Content (TPC): Total Phenolic Content was determined by using Folin-Ciocalteu (FC) reagent with analytical grade gallic acid as the standard (Marinova et al., 2005). Extract or standard solution $(15.62-500 \mathrm{mg} / \mathrm{l})$ of $1 \mathrm{ml}$ was added to distilled water $(9 \mathrm{ml})$. Then $1 \mathrm{ml} \mathrm{FC}$ reagent $(10$ times diluted with distilled water) was added. After 5 minutes; $10 \mathrm{ml} 7 \% \mathrm{Na}_{2} \mathrm{CO}_{3}$ was added to the mixture and kept for 30 minutes at room temperature. Then absorbance was measured against blank at 750 $\mathrm{nm}$ using UV spectrophotometer. Total phenolic content of the extract was determined from the standard curve and expressed as mg gallic acid equivalent (GAE)/100 g dried plant material.

iii) Determination of total flavonoid content (TFC): Total flavonoid content was determined in the sample extract by reaction with sodium nitrite, followed by the development of coloured flavonoid-aluminum complex formation using aluminum chloride in alkaline condition which can be monitored spectrophotometrically at maximum wavelength of $369 \mathrm{~nm}$ (Bakar et al., 2009).

\section{Evaluation of Chemopreventive Activity}

i) Induction of tumor: The hairs on the dorsal region of mice were shaven 3 days before the commencement of the experiment. For the induction of the tumours, a two stage protocol consisting of initiation with a single topical application of carcinogen DMBA followed two weeks later by a promoter, croton oil, three times a week, were employed as per our previous modified method of Berenblum,1941 (Prashar \& Kumar, 1994).

Four groups (10 animals per group) of Swiss albino mice were used for the study. Animals were dorsally shaved with hair clipper. Group-I was served as negative control whichwas given $2 \%$ Tween 80 in water $(10 \mathrm{ml} / \mathrm{kg}$ bodyweight $)$ orally and $50 \mu \mathrm{L}$ of 
acetone topically on their shaven back. Group-II was treated as carcinogenic control andreceived a single topical application of DMBA $(100 \mu \mathrm{g}$ in $50 \mu \mathrm{L}$ of acetone per animal) on their shaven back. Two week after the DMBA application, $0.1 \mathrm{ml}$ of $1 \%$ croton oil in acetone was topically applied three times per a week until the termination of the experiment at 16 weeks. Group-III and IVwere served as test groups and treated orally with the ethanolic extract of fruits of $C$. nucifera at dose of $250 \mathrm{mg} / \mathrm{kg}$ body weight and $500 \mathrm{mg} / \mathrm{kg}$ body weight respectively from 15 days before initiation of carcinogenesis by DMBA and continued throughout the experimental protocol on daily basis.

ii) Tumor study: Tumour incidence, tumour yield, and tumour burden were calculated after the termination of the experiment. Tumor incidence: The number of mice carrying at least onetumor, expressed as a percentage incidence. Tumor yield: The average number of papilloma per mouse. Tumor burden: The average number of tumors per tumorbearing mouse.

Biochemical study of tumor and liver sample: Tissue homogenate was prepared as described previously by Sharma et al., 2010. Determination of total protein concentration was performed following the method described by Lowry et al., 1951. Reduced glutathione (GSH) was estimated using the method of Ellman et al., 1959. Misra \& Fridorich (1972) described the basis for the assay of Superoxide Dismutase (SOD) enzyme, which involved auto-oxidation of epinephrine to adrenochrome by superoxide radicals. This method was followed for SOD analysis. Catalase (CAT) activity was evaluated following the method developed by Bergmeyer, H. U. (1983), which is based of $\mathrm{H}_{2} \mathrm{O}_{2}$ degradation by the action of CAT.

Statistical analysis: Values are presented as mean \pm SE. The data obtained from different groups was analyzed by Student's t-test. The value $P \leq 0.05$ was considered statistically significant for all conducted experiments.

\section{RESULTS AND DISCUSSION}

Antioxidant study: To evaluate the antioxidant activity DPPH radical scavenging activity was performed.The ethanolic fruits extract of $C$. nucifera, showed $\mathrm{IC}_{50}$ value as $44.67 \mu \mathrm{g} / \mathrm{ml}$, while the standard ascorbic acid showed $\mathrm{IC}_{50}$ value $7.71 \mu \mathrm{g} / \mathrm{ml}$ (Figure 1). Activity was increased linearly in concentration dependent manner at lower concentration, and saturation was reached at higher concentration for both extract and standard.In addition, total phenolic, flavonoid and tannin content of the extract were also measured and the values are $537.89 \mathrm{GAE} / 100 \mathrm{gm}$ (Figure 2), $40.69 \mathrm{mg} \mathrm{QE} / 100 \mathrm{gm}$ (Figure 3) and $44.61 \mathrm{mg}$ of GAE/100 gm (Figure 4) of dry powder of $C$. nucifera respectively. These findings justify the antioxidant properties this plant extract. 


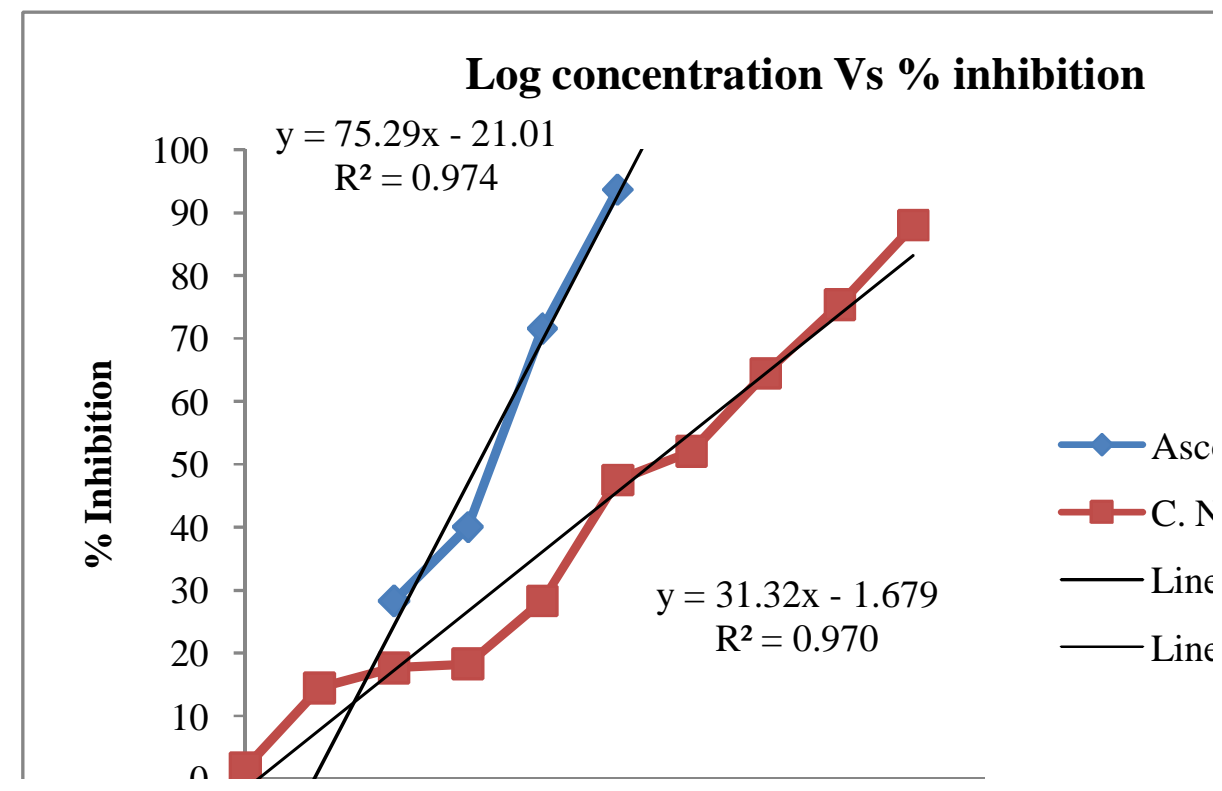

Fig. 1. DPPH scavenging assay of $C$. nucifera tender fruits

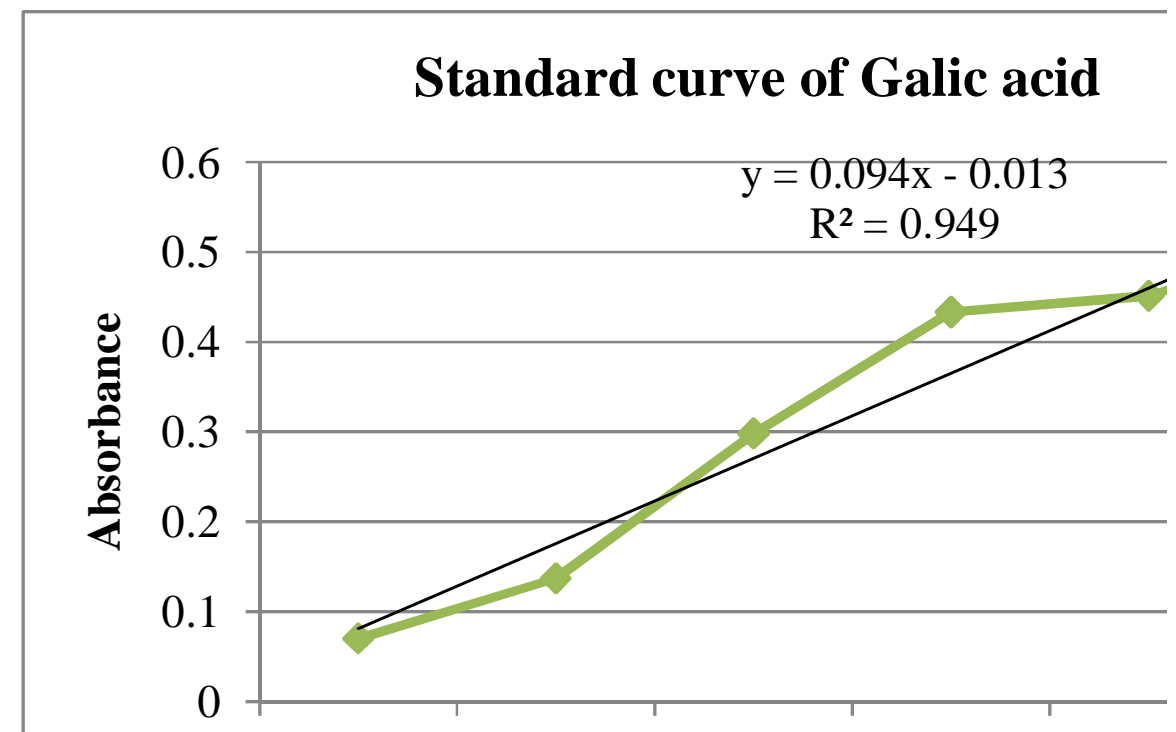

Fig. 2. Standard calibration curve of Gallic acid to determine total phenolic content of $C$. nucifera fruits 


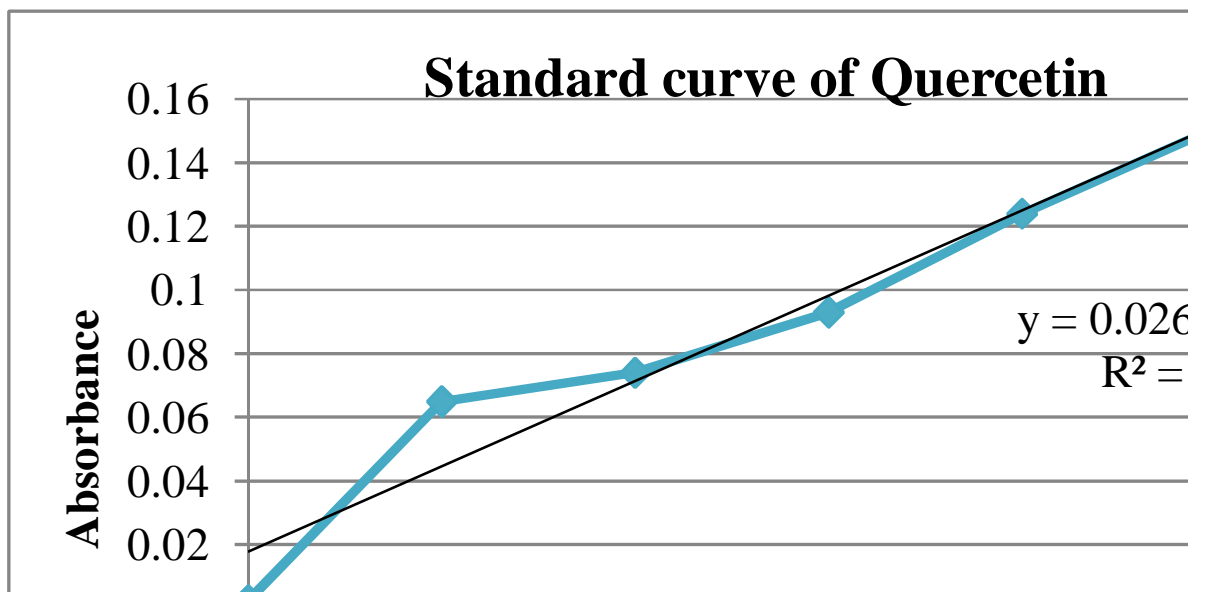

Fig. 3. Standard calibration curve of Quercetion to determine total flavonoids content of $C$. nucifera

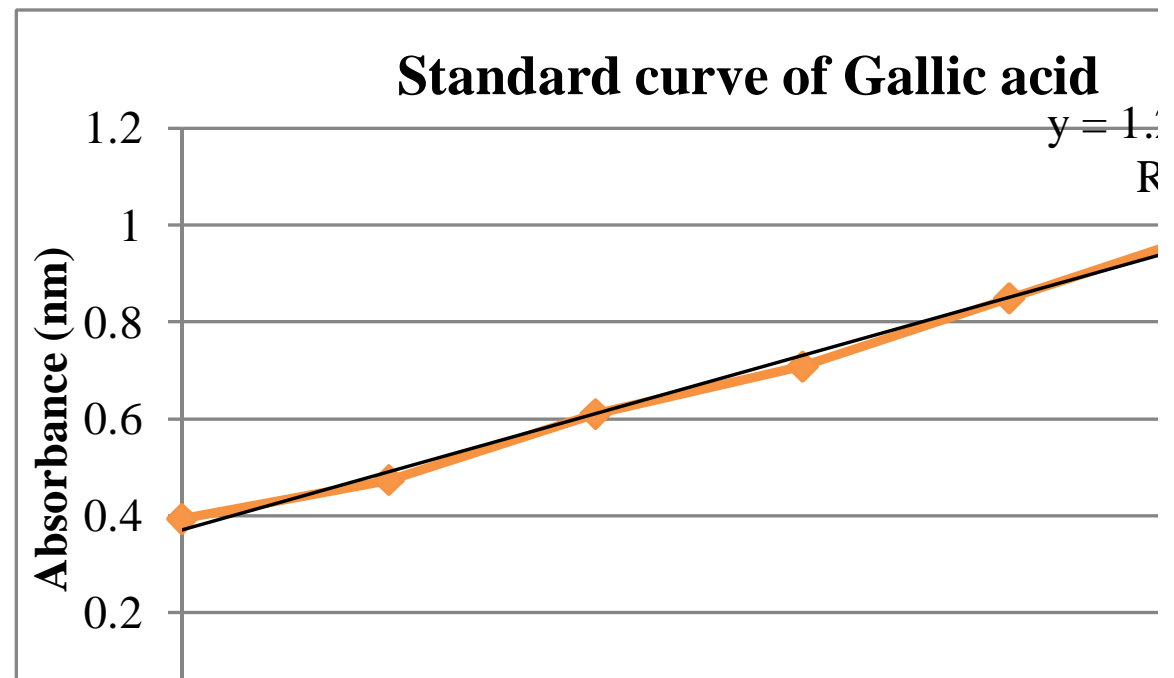

Fig. 4. Standard calibration curve of Gallic acid to determine total tannin content of $C$. nucifera fruits

Biochemical study: Oral administration of $C$. nucifera fruits extract at both doses $(250 \mathrm{mg} / \mathrm{kg}$ and $500 \mathrm{mg} / \mathrm{kg}$ body weight) significantly increased reduced gluthione (GSH), superoxide dismutase (SOD) and catalase (CAT) as compared to control group (Figures 6, $7,8)$. The extract reduced the SGPT and SGOT and brought back to about normal level (Figure 9). It did not show any remarkable impact on blood cholesterol, HDL, LDL and triglyceride (Figure 10). These indicate that the extract of $C$. nucifera has protective effect on liver and no impact on lipid profiling in blood. 
Tumour study: Tumour incidence, yield, and burden were decreased significantly and dose dependently as compared to carcinogen control (alone with DMBA \& croton oil) as shown in Table 1.

Table 1. Chemopreventive effect of $C$. nucifera on DMBA-induced skin carcinogenesis in mice

\begin{tabular}{|c|c|c|c|c|c|c|}
\hline \multirow{2}{*}{ Group } & \multicolumn{2}{|c|}{ Body weight } & \multirow{2}{*}{$\begin{array}{c}\text { Tumor } \\
\text { Incidence } \\
(\%)\end{array}$} & \multirow{2}{*}{$\begin{array}{l}\text { Tumor } \\
\text { yield }\end{array}$} & \multirow{2}{*}{$\begin{array}{l}\text { Tumor } \\
\text { burden }\end{array}$} & \multirow{2}{*}{$\begin{array}{c}\text { Tumor } \\
\text { weight (mg) }\end{array}$} \\
\hline & Initial & Final & & & & \\
\hline $\begin{array}{c}\text { Negative } \\
\text { control }\end{array}$ & $21.94 \pm 0.33$ & $37.33 \pm 0.55$ & $x_{1}(10)$ & 0 & 0 & 0 \\
\hline $\begin{array}{l}\text { Carcinogenic } \\
\text { control }\end{array}$ & $21.68 \pm 0.51$ & $30.0 \pm 0.59$ & 100 & $10.71 \pm 1.77$ & $10.71 \pm 1.77$ & 1026 \\
\hline $\begin{array}{c}\text { Test-I } \\
(250 \mathrm{mg} / \mathrm{kg})\end{array}$ & $24.08 \pm 0.865$ & $29.125 \pm 1.41$ & 90.91 & $2.72 \pm 0.589^{*}$ & $3.00 \pm 0.577 *$ & 446 \\
\hline $\begin{array}{c}\text { Test-II } \\
(500 \mathrm{mg} / \mathrm{kg})\end{array}$ & $29.08 \pm 1.018$ & $37 \pm 1.264$ & 83.33 & $2.17 \pm 0.477 *$ & $2.6 \pm 0.244^{*}$ & 316 \\
\hline
\end{tabular}

Values are expressed as mean \pm standard error of mean. $(\mathrm{n}=10) ; * \mathrm{P} \leq 0.001$ when compared with Carcinogenic control

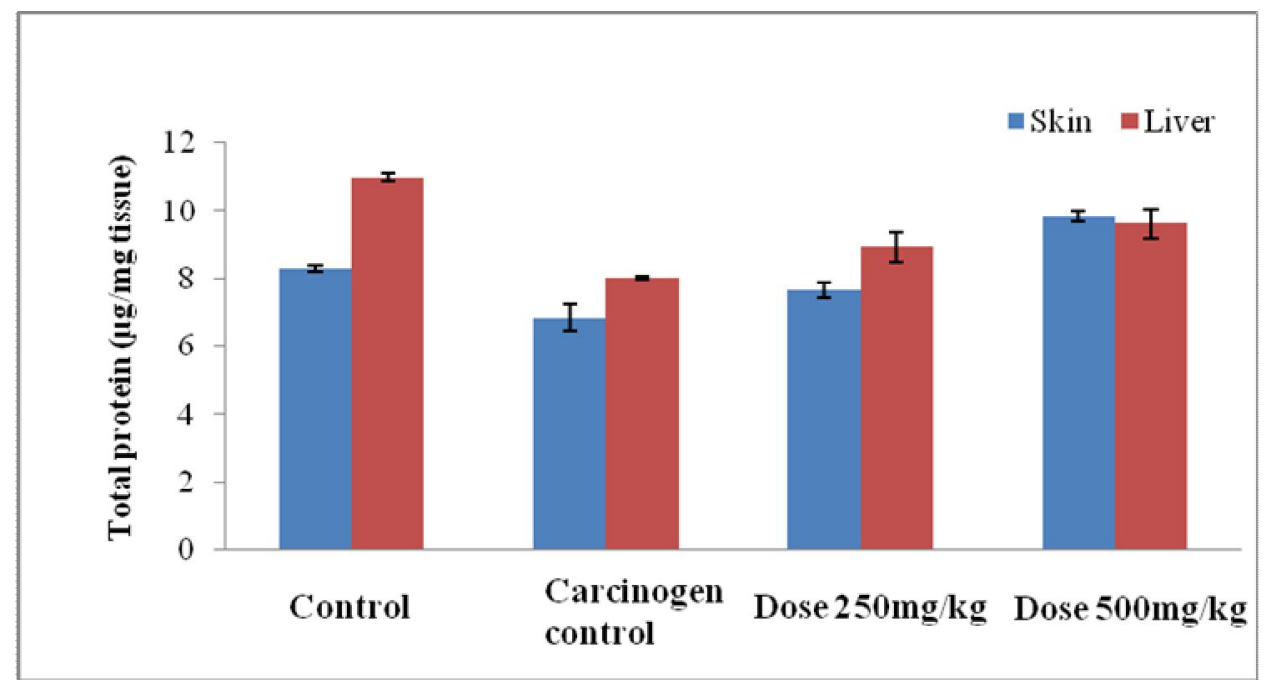

Fig. 5. Protein concentration $(\mu \mathrm{g} / \mathrm{mg})$ of sample tissue

Values are expressed as mean \pm standard error of mean. $(\mathrm{n}=10)$. $\# P \leq 0.01$, when compared with control; ** $P \leq 0.01$ when compared with carcinogenic control 


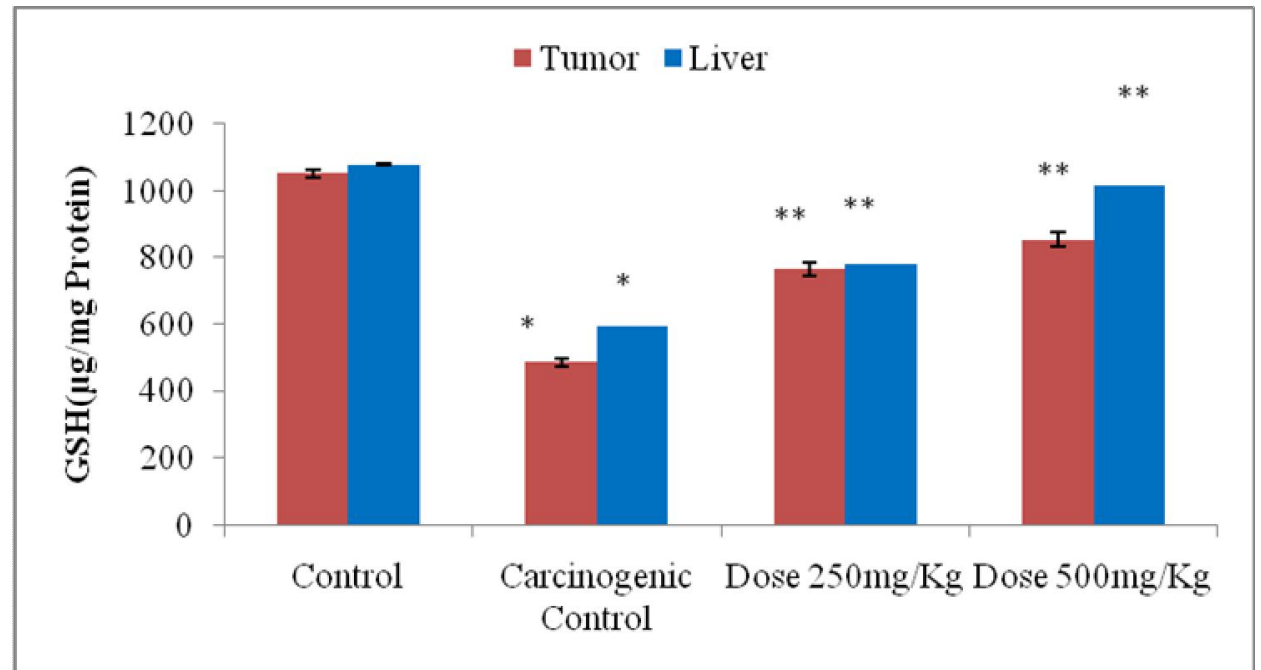

Fig. 6. GSH concentration ( $\mu \mathrm{g} / \mathrm{mg}$ protein) of sample tissue

Values are expressed as mean \pm standard error of mean. $(\mathrm{n}=10)$. $\# P \leq 0.001$ when compared with control; , * $P \leq 0.01$ when compared with Carcinogenic control

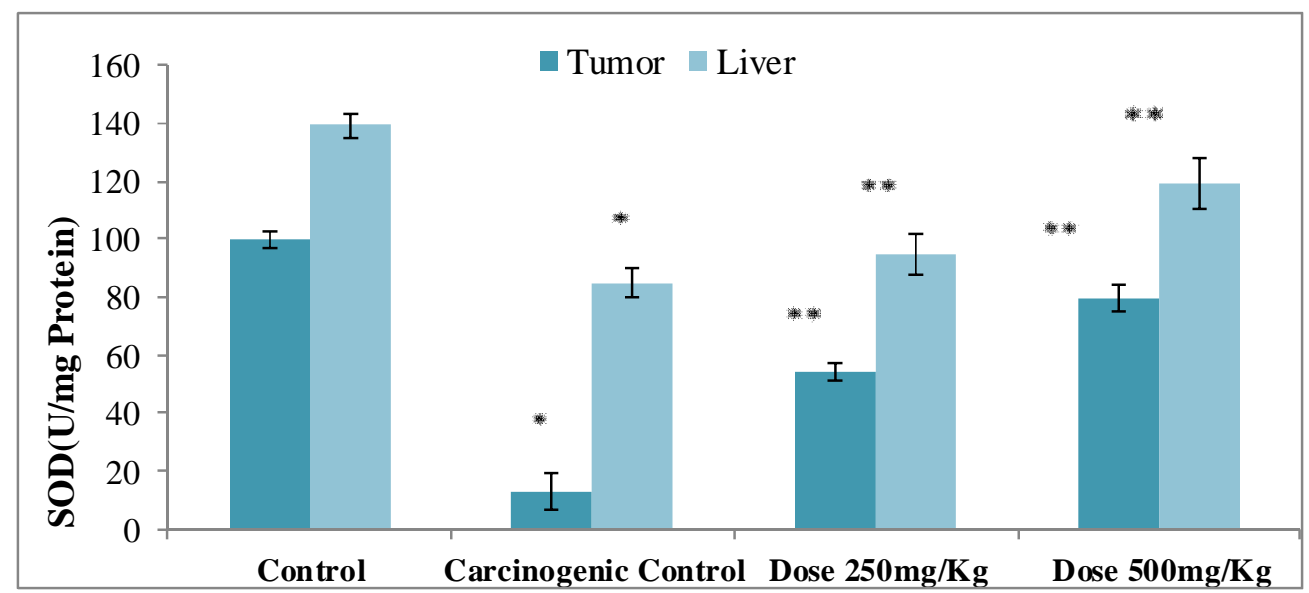

Fig. 7. SOD concentration (U/mg protein) of sample tissue

Values are expressed as mean \pm standard error of mean. $(n=10)$. \#P $\leq 0.001$ when compared with control; , ** $\mathrm{P} \leq 0.001$ when compared with Carcinogenic control 


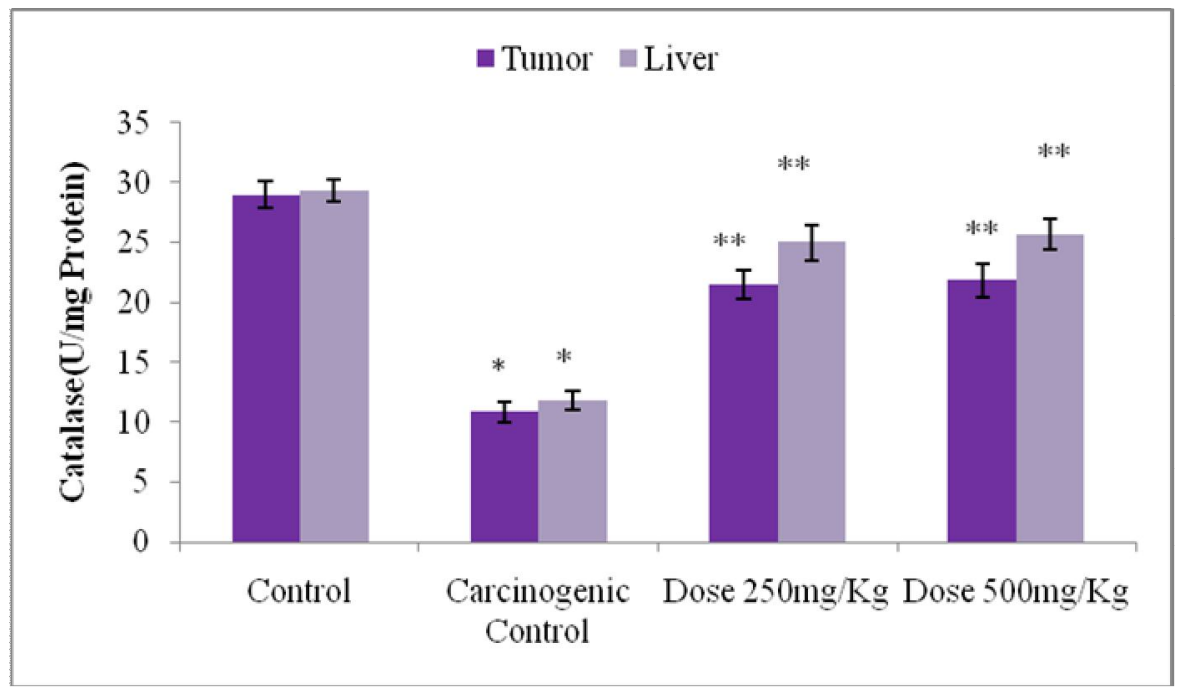

Fig. 8. Catalase concentration (U/mg protein) of sample tissue

Values are expressed as mean \pm standard error of mean. $(\mathrm{n}=10)$. $\# P \leq 0.001$ when compared with control; , * $P \leq 0.001$ when compared with Carcinogenic control

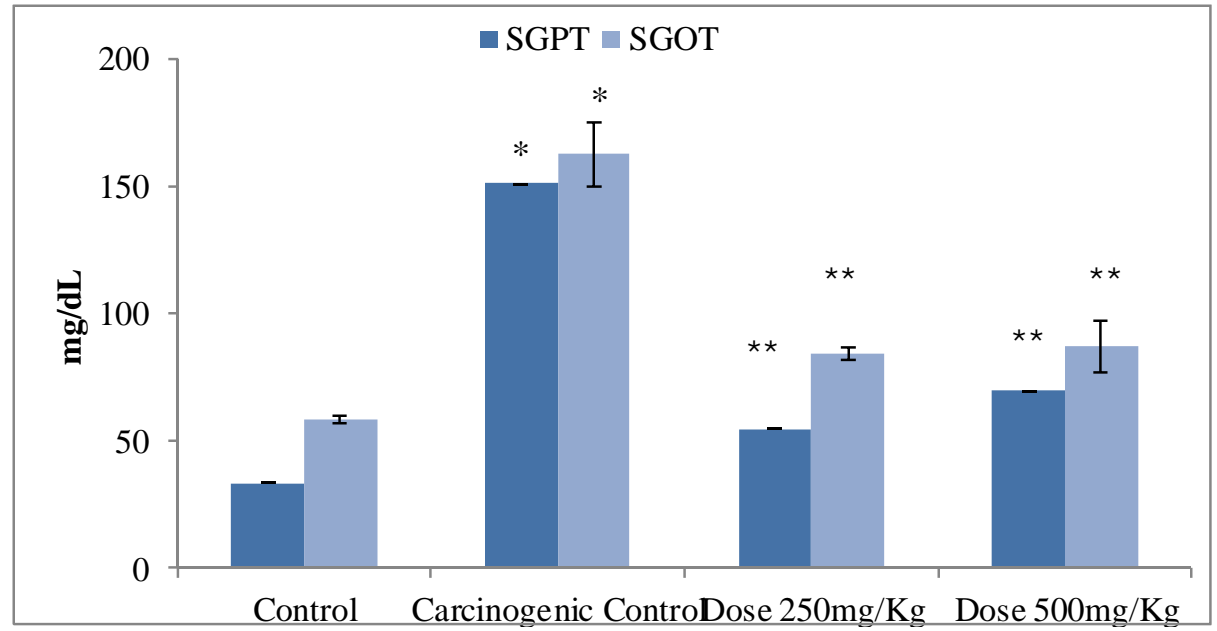

Fig. 9. sGPT, sGOT level in mice blood sample

Values are expressed as mean \pm standard error of mean. $(\mathrm{n}=10)$. \#P $\leq 0.001$ when compared with control; , ${ }^{*} P \leq 0.001$ when compared with Carcinogenic control 


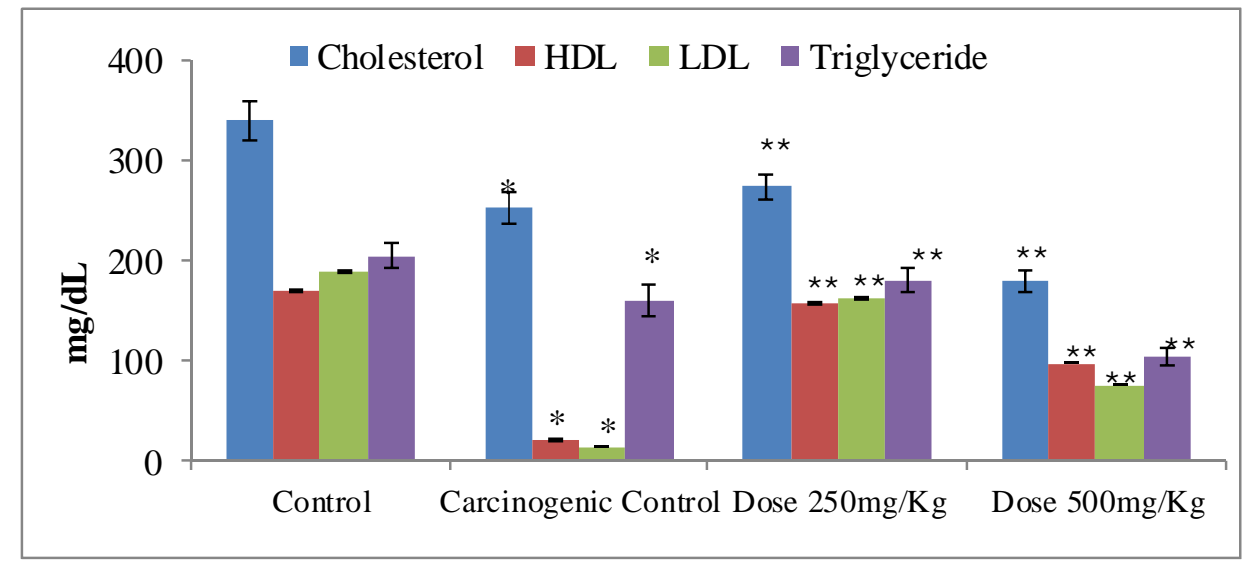

Fig. 10. Lipid profile of mice blood sample

Values are expressed as mean \pm standard error of mean. $(n=10)$. \#P $\leq 0.0001$ when compared with control, $* * P \leq 0.0001$ when compared with Carcinogenic control

Chemoprevention is an important strategy to control the process of carcinogenesis. Thus, there is a need for exploring drugs/agents which act as chemo preventive agents. In the present study, we have studied the chemo preventive effect of $C$. nucifera tender fruits using a mouse skin carcinogenesis model. Oral administration of ethanolic extract of $C$. nucifera fruits was found to be effective in reducing the tumor incidence and tumor burden in DMBA induced skin papilla magenesis (Table 1). We also observed that tumor appearance was delayed at the initiation and promotional stages of carcinogenesis in mice treated withethanolic extract of $C$. nucifera. The result of this study substantiates the anticarcinogenic activities of $C$. nucifera fruits reported by other researchers in different in vitro studies (Padumadasa et al., 2016). In vitro study is less precise than in vivo study because it does not stimulate all the biologic variables found within the human body or any other living system.

In the present study the data indicate the protein damage in skin and liver may be due to oxidative stress generated by DMBA/croton oil. In test group, oral administration of $C$. nucifera fruits elevated the level of protein as compared to Carcinogenic control group (Figure 5). Again the reduced form of GSH is a biologicalantioxidant present in high amounts and its presence is a pre-requisite for protection against oxidative damage (Dhawan et al.,1999). This is evident even as seen with this treatment, which protects the losses in GSH levels provoked by DMBA treatment and this effect was exerted in a dose dependent manner (Fig. 6).

There was a significant enhancement in the level ofGSH, SOD, and Catalases in the $C$. nucifera treated group compared to carcinogenic control group animals (Fig. 6, $7 \&$ 8). The beneficial action of $C$. nucifera is probably due to its ability to stimulate the antioxidant enzymes in the cells. This increase in enzyme activity effectively reduced the 
generation of reactive oxygen species (ROS) in the skin and thus might reduce the incidences of skin papillomas on the treated areas.Superoxide dismutase is specialized to convert the highly toxic superoxide radical to less toxic $\mathrm{H}_{2} \mathrm{O}_{2}$. The Catalase reduces $\mathrm{H}_{2} \mathrm{O}_{2}$ to $\mathrm{H}_{2} \mathrm{O}$. We also measured blood biochemical parameters, including enzymes and lipid profile, to evaluate organ function in our experimental animals. There was a significant decrease in SGOT, and SGPT levels as compared to Carcinogenic control group (Fig. 9).

The lipid profile of Carcinogenic control mice showed significant decreases in serum cholesterol, triglyceride, LDL and VLDL, HDL level when compared with negative control mice. Whereas, lipid profile of mice treated with $C$. nucifera was brought back to normal level to some extent.(Fig. 10)

It's been suggested by several authors that, chemo preventive substances exhibit antioxidant, antimutagenic and anti-inflammatory activities capable of arresting proliferation and enhancing apoptosis of cancer cells and these properties contribute to their anti-carcinogenic activity (Qiblawi et al., 2012). In the present study, several antioxidant activity tests revealed that, the $C$. nucifera contain substantial amount of flavonoids, tannin and other phenolic compounds. This supports the rational basis of chemo preventive action of $C$. nucifera.

The present study suggests that the ethanol extract of $C$. nucifera tender fruit has potential antioxidant, and chemo preventive activity. The results are quite promising and demand for further investigations.

Acknowledgements: We authors are grateful to the authorities of Phytochemistry and Pharmacology Research Laboratory, Pharmacy Discipline, Life Science School, Khulna University, Bangladesh for providing instrumental facilities.

\section{REFERENCES}

Abu Bakar, M.F., Mohamed, M., Rahmat, A. and Fry, J. 2009. Phytochemicals and antioxidant activity of different parts of bambangan (Mangifera pajang) and tarap (Artocarpus odoratissimus). Food Chemistry. 113: 479-483.

Babior, B.M. 2000. Phagocytes and oxidative stress. Am J Med. 109:33-44.

Berenblum, I. 1941. The mechanism of carcinogenesis: A study of the significance of the cocarcinogenic action and related phenomena. Cancer Res. 1, 807-14.

Braca, A., Sortino, C., Politi, M., Morelli, I. and Mendez, J. 2002. Antioxidant activity of flavonoids from Licanialicaniae flora. J Ethnopharmacol. 79:379-81.

Dhawan, D., Balasubramanian, S., Amonkar, A.J. and Singh, S. 1999. Chemopreventive effect of 4-demethyl epipodophyllotoxin on DMBA/TPA induced mouse skin carcinogenesis. Carcinogenesis, 20: 997-1003.

Swerdlow, A.J., Peto, R. and Doll, R. 2010. Epidemiology of Cancer in Oxford Textbook of Medicine; $5^{\text {th }}$ ed. USA: Oxford University Press. pp. 299-305.

Edward, C. and Craig, R.E. 2006. Cocos nucifera. In Species Profile for Pacific Island Agroforestry; Permanent Agriculture Resources: Holualoa, HI.

Enig, M. 2000. Know Your Fats-The Complete Primer for Understanding the Nutrition of Fats, Oils and Cholesterol; Bethesda Press: Silver Spring, Maryland, MD, USA. 
Esquenazi, D., Wigg, M.D., Miranda, M.M. and Rodrigues, H.M., Tostes, J.B., Rozental, S., da Silva, A.J.R. and Alviano, C.S. 2002. Antimicrobial and antiviral activities of polyphenolics from Cocos nucifera Linn. (Palmae) husk fiber extract. Res. Microbiol., 153, 647-652.

Kelloff, G.J. 2008. Perspectives on cancer chemoprevention research and drug development. Adv Cancer Res., 78:199-334.

Lima, E.B.C., Sousa, C.N.S., Meneses, L.N., Ximenes, N.C., Santos, Júnior, M.A., Vasconcelos, G.S., Lima, N.B.C., Patrocínio, M.C.A., Macedo, D. and Vasconcelos, S.M.M. 2015. Cocosnucifera (L.) (Arecaceae): A phytochemical and pharmacological review. Braz J Med Biol Res., 48(11): 953-964.

Marinova, D., Ribarova, F. and Atanassova, M. 2005. Total phenolics and total flavonoids in Bulgaria fruits and vegetables. J Univ. Chem. Technol and Metall., 40: 255-260.

Maxwell, S.R. 1995. Prospects for the use of antioxidant therapies. Drugs. 49:345-61

Nipun, D., Vijay, S., Jaykumar, B., Kirti, S.P. and Richard, L. 2011. Antitumor Activity of Dendrophthoe falcata against Ehrlich Ascites Carcinoma in Swiss Albino Mice. Pharma Crops. 2:1-7

Padumadasa, C., Dharmadana, D., Abeysekera, A. and Thammitiyagodage, M. 2016. In vitro intioxidant, anti-inflammatory and anticancer activities of ethyl acetate soluble proanthocyanidins of the inflorescence of Cocosnucifera L. BMC Complement Altern Med.,16:345-50.

Prashar, R. and Kumar, A. 1994. Chemo preventive action of Ocimum sanctum on DMBA Induced pappilomagenesis in the skin of mice. Int J Pharm. 33/2, 181-18.

Prashar, R. and Kumar, A. 1995. Chemo preventive action of Ocimum sanctum on DMBA Induced pappilomagenesis in the skin of mice. Int J Pharm., 33/2, 181-7.

WHO Factsheet about cancer. 2017 (http://www.who.int/mediacentre/factsheets/fs297/en/) 